\title{
Reversal of SARS-CoV2-Induced Hypoxia by Nebulized Sodium Ibuprofenate in a Compassionate Use Program
}

\author{
Oscar Salva · Pablo A. Doreski · Celia S. Giler · Dario C. Quinodoz • Lucia G. Guzmán · Sonia E. Muñoz • \\ Mariana N. Carrillo • Daniela J. Porta • Germán Ambasch • Esteban Coscia • Jorge L. Tambini Diaz • \\ Germán D. Bueno · Jorge O. Fandi · Miriam A. Maldonado · Leandro E. Peña Chiappero · Fernando Fournier • \\ Hernán A. Pérez · Mauro A. Quiroga · Javier A. Sala Mercado · Carlos Martínez Picco • Marcelo Alejandro Beltrán • \\ Luis A. Argañarás · Nicolás Martínez Ríos · Galia I. Kalayan · Dante M. Beltramo • Néstor H. García (D)
}

Received: April 14, 2021 / Accepted: August 12, 2021 / Published online: August 30, 2021

(c) The Author(s) 2021

\section{ABSTRACT}

Introduction: Sodium ibuprofenate in hypertonic saline (NaIHS) administered directly to the lungs by nebulization and inhalation has antibacterial and anti-inflammatory effects, with the potential to deliver these benefits to

Dr. Salva and Dr. Doreski contributed equally to this article.

Supplementary Information The online version contains supplementary material available at https:// doi.org/10.1007/s40121-021-00527-2.

O. Salva · C. S. Giler · J. O. Fandi

Clínica Independencia, Munro, Buenos Aires, Argentina

\section{P. A. Doreski}

Fundación Respirar, Belgrano, Buenos Aires, Argentina

D. C. Quinodoz · L. G. Guzmán

Sanatorio de la Cañada, Villa Maria, Córdoba, Argentina

S. E. Muñoz · M. N. Carrillo · D. J. Porta ·

N. H. García

Instituto de Investigaciones en Ciencias de la Salud,

Ciudad Universitaria, Córdoba, Argentina

G. Ambasch - E. Coscia - J. L. T. Diaz - G. D. Bueno Sanatorio Mayo Privado SA, Ciudad de Córdoba, Córdoba, Argentina

M. A. Maldonado · L. E. Peña Chiappero Hospital San Roque, Ciudad de Córdoba, Córdoba, Argentina hypoxic patients. We describe a compassionate use program that offered this therapy to hospitalized COVID-19 patients.

Methods: NaIHS (50 mg ibuprofen, tid) was provided in addition to standard of care (SOC) to hospitalized COVID-19 patients until oxygen saturation levels of $>94 \%$ were achieved on ambient air. Patients wore a containment hood to diminish aerosolization. Outcome data from participating patients treated at multiple hospitals in Argentina between April 4 and October 31,2020 , are summarized. Results were

F. Fournier

Clínica Francesa, Ciudad de Mendoza, Mendoza, Argentina

H. A. Pérez

Sanatorio Alive, Ciudad de Córdoba, Córdoba, Argentina

\section{H. A. Pérez}

Department of Diagnostic Radiology and Nuclear Medicine, Center for Advanced Imaging Research, Maryland University, Baltimore, MD, USA

\section{A. Quiroga · J. A. Sala Mercado}

Instituto Modelo de Cardiología, Ciudad de Córdoba, Córdoba, Argentina

C. Martínez Picco

Clínica del Sol, Ciudad de Rivadavia, Mendoza, Argentina

M. A. Beltrán

Hospital Dr. Alberto Duhau, José C Paz, Buenos Aires, Argentina 
compared with a retrospective contemporaneous control (CC) group of hospitalized COVID19 patients with SOC alone during the same time frame from a subset of participating hospitals from Córdoba and Buenos Aires.

Results: The evolution of 383 patients treated with SOC + NaIHS [56 on mechanical ventilation (MV) at baseline] and 195 CC (21 on MV at baseline) are summarized. At baseline, NaIHStreated patients had basal oxygen saturation of $90.7 \pm 0.2 \% \quad(74.3 \%$ were on supplemental oxygen at baseline) and a basal respiratory rate of $22.7 \pm 0.3 \mathrm{breath} / \mathrm{min}$. In the CC group, basal oxygen saturation was $92.6 \pm 0.4 \%(52.1 \%$ were on oxygen supplementation at baseline) and respiratory rate was $19.3 \pm 0.3$ breath $/ \mathrm{min}$. Despite greater pulmonary compromise at baseline in the NaIHS-treated group, the length of treatment (LOT) was $9.1 \pm 0.2$ gs with an average length of stay (ALOS) of $11.5 \pm 0.3$ days, in comparison with an ALOS of $13.3 \pm 0.9$ days in the CC group. In patients on MV who received NaIHS, the ALOS was lower than in the CC group. In both NaIHS-treated groups, a rapid reversal of deterioration in oxygenation and NEWS2 scores was observed acutely after initiation of NaIHS therapy. No serious adverse events were considered related to ibuprofen therapy. Mortality was lower in both NaIHS groups compared with CC groups.

Conclusions: Treatment of COVID-19 pneumonitis with inhalational nebulized NaIHS was associated with rapid improvement in hypoxia and vital signs, with no serious adverse events attributed to therapy. Nebulized NaIHS s worthy of further study in randomized, placebo-controlled trials (ClinicalTrials.gov: NCT04382768).

\footnotetext{
L. A. Argañarás · N. M. Ríos

Química Luar SRL, Ciudad de Córdoba, Córdoba, Argentina

G. I. Kalayan · D. M. Beltramo · N. H. García (凶) CEPROCOR, Ciudad de Santa María de Punilla, Córdoba, Argentina

e-mail: garcia.nestor@conicet.gov.ar

D. M. Beltramo

CONICET, Ciudad de Santa María de Punilla,

Córdoba, Argentina
}

Keywords: Acute respiratory distress syndrome; Coronavirus; COVID-19; Hypoxemia; SARS-CoV-2; Viral pneumonia

\section{Key Summary Points}

\section{Why carry out this study?}

Disease due to severe acute respiratory syndrome coronavirus 2 (SARS CoV-2), COVID-19, has taken the world by storm.

Inhalation of anti-inflammatory therapy may have a positive effect on hospitalized patients with moderate to severe COVID19.

\section{What was learned from the study?}

Hospitalized patients with moderate to severe COVID-19 may benefit from inhalation ibuprofen therapy in terms of oxygenation improvement and length of hospital stay.

Sodium ibuprofenate in hypertonic saline (NaIHS) compared with a contemporaneous control, appears to be a promising therapy for treatment of COVID-19 pneumonitis, warranting further evaluation in randomized controlled trials.

\section{INTRODUCTION}

Disease due to severe acute respiratory syndrome coronavirus 2 (SARS CoV-2), COVID-19, has taken the world by storm. As of this writing, an estimated 188 million cases and more than 4 million deaths have been recorded by the World Health Organization [1], and effective therapy options remain limited. To date, dexamethasone, tofacitinib (a Janus kinase inhibitor), and monoclonal antibody therapies have demonstrated benefit in patients with severe illness [2], while evidence of benefit for many other drugs remains unknown [3] or disproven [4-7]. 
A hallmark of severe COVID-19 is profound hypoxia, which may progress to acute respiratory distress syndrome (ARDS). Clinically, these changes are accompanied by characteristic ground glass infiltrates on chest tomography and significant hypoxia [8]. In autopsy series, several notable features have been described, including diffuse alveolar damage with perivascular T-cell infiltration, severe endothelial injury with intracellular virus, widespread thrombosis with microangiopathy, and intussusceptive angiogenesis and pathological vascular dilation in diseased areas of the lungs [9].

In severe COVID-19, local release of autacoids leading to vascular injury and permeability results in excess alveolar fluid protein accumulation. This phenomenon, coupled with vasodilation and intrapulmonary shunting of non-oxygenated blood, has been characterized as a 'bradykinin storm' [10], based on the observation of reduced ACE expression (with corresponding local loss of vasoconstriction), while ACE2, bradykinin, and kallikrein expression were increased in diseased tissues. This mismatch contributes to ventilation/perfusion mismatch and resulting hypoxia. This hypothesis has been supported by the demonstration of intrapulmonary shunting in severe COVID-19 [11]. Importantly, ibuprofen can prevent bradykinin-induced inflammation at the respiratory mucosa [12], and it has also been demonstrated to prevent bradykinin-induced vascular extravasation and angioedema in humans [13]. These data suggest that ibuprofen may mitigate this aspect of the inflammatory response in COVID-19.

Widespread occlusion of pulmonary vasculature by microthrombi has been well demonstrated [14], with evidence that over $50 \%$ of patients dying of COVID-19 have pulmonary microthromboses. Thromboses are found not only in arterial vessels but also in alveolar capillaries, including in the absence of overt inflammation and ARDS [15]. The anti-thrombotic effect of ibuprofen at low doses has been well known for decades, principally mediated via inhibition of platelet aggregation [16]. Ibuprofen is a non-selective COX2 and COX1 inhibitor, an inhibitor of synthesis of thromboxane TBX2, a platelet pro-aggregant, a vasoconstrictor, a pro-inflammatory cytokine, and an inhibitor of polymorphonuclear cell release of reactive oxygen species and inflammatory mediators [17-20].

We have previously reported that sodium ibuprofenate is a membrane-penetrating amphiphatic molecule with antibacterial properties in the presence of hypertonic saline, rendering the combination bactericidal for Pseudomonas aeruginosa and Burkholderia cepacian [21].

Viruses transiting cell membranes must navigate the actin-cytoskeleton of the target cell, a process regulated by Rho GTPase family members [22]. Denison and colleagues demonstrated that SARSCoV-1 induces continuous macropinocytosis and extensive filopodia outgrowth, and that inhibition of this process impaired virus replication [23]. In a dengue virus model, activation of the GTPases, Rac1 and Cdc42, and resulting filopodia growth was essential for virus entry and productive infection [24]. These authors noted that insulin and bradykinin, respectively, serve as agonists (activators) for these two GTPases (this tantalizing side note may ultimately shed light on the observation that COVID19 is much more severe in patients with elevated insulin levels in the setting of type 2 diabetes). Ibuprofen inhibits Rho GTPase activation $[25,26]$, including Rac1b through a non-cyclooxygenase-inhibiting pathway. Thus, additional activities of ibuprofen may also have indirect antiviral properties relevant to SARS-CoV2.

Given these potential benefits of sodium ibuprofenate in hypertonic saline (NaIHS) in the context of SARS-CoV2 pneumonitis, we designed a compassionate-use program to offer this potentially beneficial therapy in the face of a pandemic pathogen against which few therapeutic options were available.

\section{METHODS}

Ethical approval was obtained from the Institutional Independent Ethics Committees and district regulatory agencies of Córdoba and Mendoza Provinces for the compassionate use of Luarprofeno $^{\circledR} \quad$ (sodium ibuprofenate in 
hypertonic saline for nebulization) (hereafter, NaIHS). The program was carried out in accordance with the principles of the Declaration of Helsinki for Buenos Aires. This study was registered with ClinicalTrials.gov, NCT04382768. All participating individuals were $\geq$ age 18 and provided written informed consent, obtained by the treating physician.

Luarprofeno ${ }^{\circledR}$ was manufactured under GMP conditions and provided by Química Luar $(\mathrm{QL}$, Córdoba, Argentina) in sterile vials, each containing $50 \mathrm{mg}$ of sodium ibuprofenate in $5 \mathrm{~mL}$ of hypertonic saline (comprised of $29 \mathrm{mg} \mathrm{NaCl} /$ $\mathrm{mL}, \mathrm{a} \sim 3 \%$ solution). Each vial comprised $\mathrm{a}$ single dose. A three-times daily dosing schema, each dose with $50 \mathrm{mg}$ dose, was selected based on preliminary observations [21,27]. The total daily administered ibuprofen dose was therefore $\leq 150 \mathrm{mg}$, recognizing that some drug is exhaled.

To submit a drug request for patients, clinicians from Córdoba, Buenos Aires, and Mendoza completed an assessment form with demographic and disease-status information about their patients. Approval of requests was reserved for hospitalized patients who had SARS-CoV-2 infection confirmed by reverse transcriptase-polymerase chain reaction assay and pneumonia. NaIHS was also provided for a small number of patients $(<5 \%)$ with suspected COVID-19 infection based on clinician assessment, bypassing the need for SARS-CoV-2 PCR diagnostics, which were not consistently available in all regions at various times. Ibuprofen allergy was an exclusion criterion.

Each dose was administered using a standard piston-pump nebulizer, or via high-flow oxygen or compressed ambient air, by face-mask. To reduce health care worker infection risk in the setting of nebulized therapy use, a novel containment hood was utilized with air venting via antiviral filters, designed to prevent particle aerosolization. All healthcare workers utilized personal protective equipment provided by their institutions. Each nebulized dose was administered over approximately $15 \mathrm{~min}$, the time required to drain the liquid nebulization vessel. Treatment was initiated in participants with pulse oximetry saturation $\left(\mathrm{SpO}_{2}\right) \leq 94 \%$ or a need for oxygen support. Treatment was continued until $\mathrm{SpO}_{2}$ reached $\geq 94 \%$ while breathing ambient air for $\geq 24 \mathrm{~h}$. or was stopped at clinician discretion or patient request.

Supportive and standard of care (SOC) therapy was provided at the discretion of the clinician, as those therapies were available. If available, clinical status data collected by the clinician as part of SOC was to shared with QL to evaluate program safety.

One protocol amendment (notified Jun 14, 2021; granted June 17,2021 ) was made to add the contemporaneous control group. This change was made in recognition of the fact that a comparison group would strengthen the analytical effort to discern potential beneficial effects of NaIHS therapy, in support of future randomized controlled clinical trials. Four of eight institutions provided baseline characteristics, and high-level outcome data for all admitted patients with confirmed COVID19 diagnosis during the April-October time period of 2020, with information provided for 195 patients independent of the outcome and baseline conditions. All these patients were included in the analysis.

\section{Endpoint Assessments}

Patients were assessed daily during their hospitalization, from day 1 of treatment until discharge. These data were utilized to register patient clinical status based on the National Early Warning Score 2 for each day [28]. All adverse events (AE) that were considered studydrug related were recorded. Vital signs were collected under routine hospital protocols every day between 07:00 and 11:00 am, before NaIHS therapy. Outcomes in the smaller number of patients receiving mechanical ventilation (MV) support at the time of NaIHS therapy initiation are presented separately in this manuscript. The average length of stay in hospitals (ALOS) and duration of treatment (DOT) were reported.

\section{Statistical Analysis}

The analysis population included all patients with validated medical records who received compassionate use of NaIHS therapy for at least 
1 day. Statistical analysis was carried out by a dedicated medical statistician from the University of Córdoba who was independent from the study team, using STATA (v.15.0) software. Baseline characteristics and outcomes were compared between groups with use of $\chi^{2}$ tests for equality of proportions for binary data, and with independent-samples $t$ tests (for mean values) or Mann-Whitney $U$ tests (for median values) as appropriate for continuous data. Summary measures included mean and SE values. Clinical status was evaluated through the determination of $\mathrm{SpO}_{2}$ measured by pulse oximetry, respiratory rates (RR) and NEWS2 scores over time, as well as ALOS and duration of supplemental oxygen therapy. The in-hospital mortality rate was determined and compared between groups. Treatment safety was assessed based on AEs considered study-drug-related by treating physicians. To evaluate the risk of mortality according to NaIHS treatment considering the patient's biological characteristics and clinical status, a multiple logistic regression was fit. Life-status was used as the response variable; age, $\mathrm{SpO}_{2}$ (both in continuous) presence of comorbidities and status of ventilation were included in the linear predictor. The most parsimonious model with the lowest Akaike information criterion score was selected [29].

\section{RESULTS}

\section{Overall Enrollment and Baseline Characteristics}

A total of 383 patients were enrolled and received at least three doses $(50 \mathrm{mg})$ of NaIHS (Fig. 1): 253 from multiple hospitals in Córdoba Province, 95 from a single hospital in Buenos Aires, and 35 from multiple hospitals in Mendoza Province. A post hoc contemporaneous control group was identified, to enable comparisons of outcomes between patients receiving SOC versus SOC plus NaIHS. At baseline, 327 of 383 NaIHS-treated patients were not on MV (Fig. 1). Among the CC patient control group, 174 of 195 patients were not on MV at baseline.

\section{Participant enrollment, Compassive-use nebulized ibuprofen therapy for moderate to severe COVID-19 in Argentina}

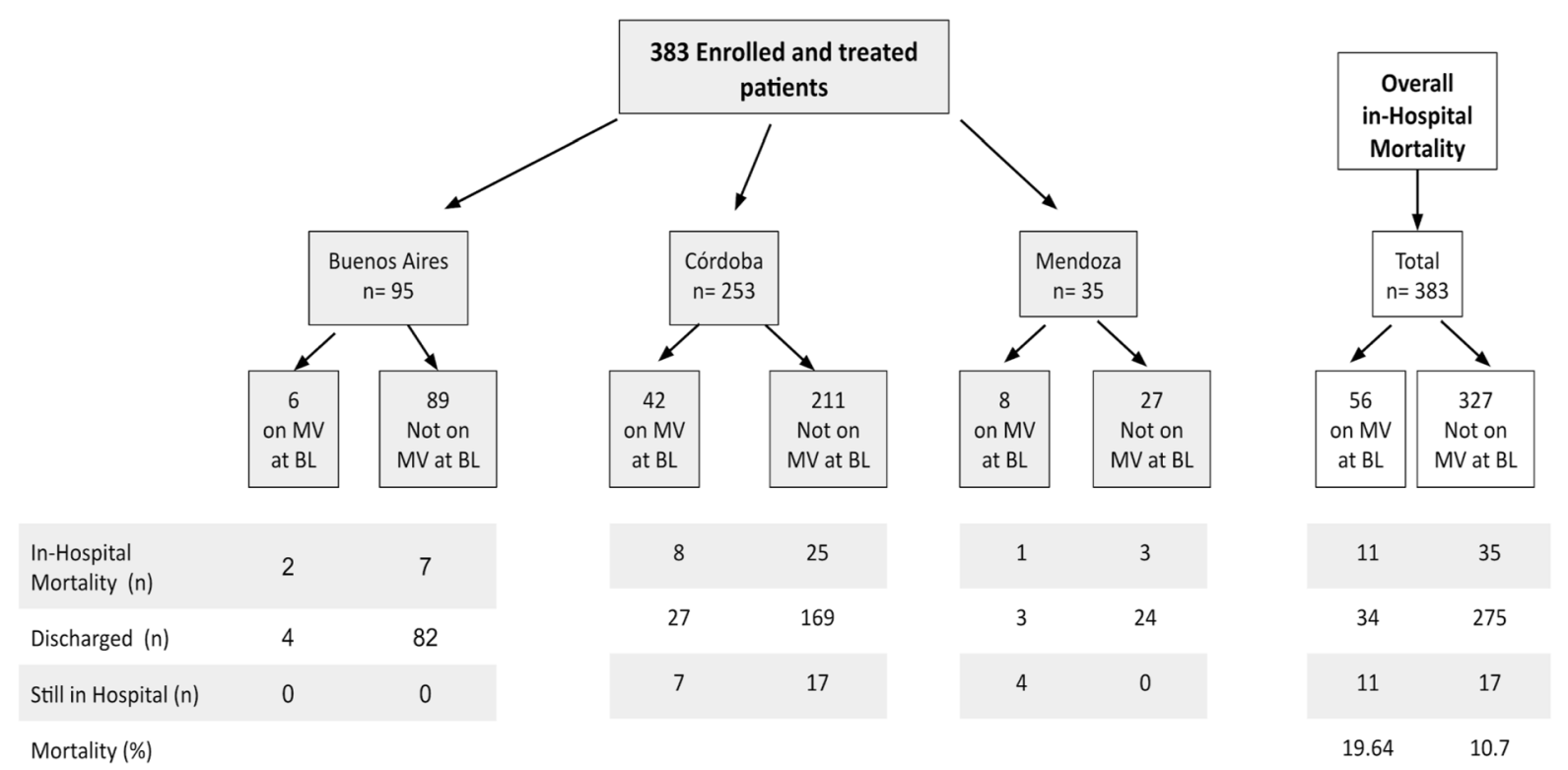

Fig. 1 Participant enrollment, compassionate-use nebulized ibuprofen therapy for moderate to severe COVID-19 in Argentina. The outcome of these patients was compared with contemporaneous controls 
Table 1 Baseline and outcome characteristics among hospitalized COVID19 patients not on mechanical ventilation at baseline

\begin{tabular}{|c|c|c|}
\hline $\begin{array}{l}\text { Baseline } \\
\text { characteristic }\end{array}$ & $\begin{array}{l}\text { Nebulized } \\
\text { ibuprofen } \\
(n=327)\end{array}$ & $\begin{array}{l}\text { Contemporaneous } \\
\text { control }(n=174)\end{array}$ \\
\hline Mean age (in years) & $59 \pm 1$ & $64 \pm 1$ \\
\hline Female patients (\%) & 37.6 & 38.1 \\
\hline \multicolumn{3}{|c|}{ Risk factors for disease severity } \\
\hline Has any risk factor & $56 \%$ & $70.1 \%$ \\
\hline Diabetes & $22 \%$ & $23 \%$ \\
\hline $\begin{array}{l}\text { Cardiovascular } \\
\text { disease (includes } \\
\text { HTN) }\end{array}$ & $43 \%$ & $62.4 \% *$ \\
\hline $\begin{array}{l}\text { Chronic lung } \\
\text { disease }\end{array}$ & $14 \%$ & $17 \%$ \\
\hline $\begin{array}{l}\text { Proportion receiving } \\
\text { supplemental } \mathrm{O}_{2} \text {, } \\
\text { day } 1\end{array}$ & $74.3 \%$ & $52.1 \%$ \\
\hline $\begin{array}{l}\text { Mean baseline } \mathrm{O}_{2} \\
\text { saturation (pulse } \\
\text { oximetry) }\end{array}$ & $90.7 \pm 0.2 \%$ & $92.6 \pm 0.4 \%^{*}$ \\
\hline $\begin{array}{l}\text { Mean baseline } \\
\text { respiratory rate } \\
\text { (breaths/min) }\end{array}$ & $22.7 \pm 0.3$ & $19.3 \pm 0.3^{*}$ \\
\hline $\begin{array}{l}\text { Baseline NEWS2 } \\
\text { Score }\end{array}$ & $7.0 \pm 0.1$ & $\mathrm{~N} / \mathrm{A}$ \\
\hline $\begin{array}{l}\text { Proportion receiving } \\
\text { dexamethasone } \\
\text { therapy (at some } \\
\text { point during } \\
\text { treatment course) }\end{array}$ & $78.4 \%$ & $94.6 \%$ \\
\hline $\begin{array}{l}\text { Average length of } \\
\text { stay (days) }\end{array}$ & $11.5 \pm 0.3$ & $13.3 \pm 0.9^{*}$ \\
\hline $\begin{array}{l}\text { Mean duration of } \\
\text { ibuprofen therapy } \\
\text { (days) }\end{array}$ & $9.0 \pm 0.2$ & $\mathrm{~N} / \mathrm{A}$ \\
\hline
\end{tabular}

Table 1 continued

\begin{tabular}{lll}
\hline $\begin{array}{l}\text { Baseline } \\
\text { characteristic }\end{array}$ & $\begin{array}{l}\text { Nebulized } \\
\text { buprofen } \\
(\boldsymbol{n}=\mathbf{3 2 7})\end{array}$ & $\begin{array}{l}\text { Contemporaneous } \\
\text { control }(\boldsymbol{n}=\mathbf{1 7 4})\end{array}$ \\
\hline $\begin{array}{l}\text { Mean time in } \\
\text { hospital to death, } \\
\text { deceased patients } \\
(n)\end{array}$ & $13 \pm 1.2$ & $19 \pm 2.8$ \\
Mortality (\%) & $35 / 327$ & $34 / 17419.5 \%^{*}$ \\
& $10.7 \%$ & \\
\hline
\end{tabular}

${ }^{*} p$ values are statistically significant between the nebulized ibuprofen-treated group and the contemporaneous control group

Outcome measures are presented separately for these two aggregate groups (Tables 1, 2). Among patients not receiving MV at baseline, general characteristics are shown in Table 1, including incidence of risk factor of diabetes, cardiovascular disease including hypertension, and chronic lung disease. In NaIHS-treated patients' baseline $\mathrm{SpO}_{2}$ was $90.7 \pm 0.2 \%$, with $74.3 \%$ of patients on supplemental oxygen at the time of measurement, while in the CC group, $\mathrm{SpO}_{2}$ was $92.6 \pm 0.4 \%(p<0.0001$ vs. NaIHS group), and only $52.1 \%$ of the patients were receiving supplemental oxygen at that time.

Among patients receiving $\mathrm{MV}$ at baseline, both groups were similar except basal $\mathrm{SpO}_{2}$ (Table 2). Prior diagnoses of diabetes, cardiovascular disease including hypertension, and chronic lung disease were similar. In the NaIHStreated group, baseline $\mathrm{SpO}_{2}$ was $90 \pm 0.8 \%$, while in the CC group, it was $83.6 \pm 1.7 \%$ $(p<0.001)$.

For a subgroup of NaIHS-treated patients not on MV $(n=60)$, the NEWS2 score (Fig. 2A), RR (Fig. $2 \mathrm{~B})$, and oxygen saturation $\left(\mathrm{SpO}_{2}\right.$, Fig. $\left.2 \mathrm{C}\right)$ were available for a period of 1-3 days prior to initiation of NaIHS therapy. Strikingly, this subgroup of patients demonstrated progressive clinical deterioration indicated by worsening NEWS2 scores prior to initiation of NaIHS therapy, with peak NEWS 2 score evident on the day of (but prior to) therapy initiation. This 
Table 2 Baseline and outcome characteristics of hospitalized COVID19 patients who received compassionate use nebulized ibuprofen therapy compared with contemporaneous controls, both on mechanical ventilation

\begin{tabular}{|c|c|c|}
\hline $\begin{array}{l}\text { Baseline } \\
\text { characteristic }\end{array}$ & $\begin{array}{l}\text { Nebulized } \\
\text { ibuprofen } \\
(n=56)\end{array}$ & $\begin{array}{l}\text { Contemporaneous } \\
\text { control }(n=21)\end{array}$ \\
\hline Mean age (in years) & $61 \pm 2$ & $70 \pm 2$ \\
\hline Female patients & $30.4 \%$ & $38.1 \%$ \\
\hline \multicolumn{3}{|c|}{ Risk factors for disease severity } \\
\hline Has any risk factor* & $69.6 \%$ & $100 \%$ \\
\hline Diabetes & $28.6 \%$ & $40.0 \%$ \\
\hline $\begin{array}{l}\text { Cardiovascular } \\
\text { disease (includes } \\
\text { HTN) }\end{array}$ & $46.6 \%$ & $76.2 \%$ \\
\hline $\begin{array}{l}\text { Chronic lung } \\
\text { disease }\end{array}$ & $23.2 \%$ & $14.3 \%$ \\
\hline $\begin{array}{l}\text { Proportion receiving } \\
\text { supplemental } \mathrm{O}_{2} \text {, } \\
\text { day } 1\end{array}$ & $100 \%$ & $100 \%$ \\
\hline $\begin{array}{l}\text { Mean baseline } \mathrm{O}_{2} \\
\text { saturation (pulse } \\
\text { oximetry) }\end{array}$ & $90.0 \pm 0.8 \%$ & $83.6 \pm 1.7 \%^{*}$ \\
\hline $\begin{array}{l}\text { Mean baseline } \\
\text { respiratory rate } \\
\text { (breaths } / \mathrm{min} \text { ) }\end{array}$ & $23 \pm 0.8$ & $24 \pm 1.0$ \\
\hline $\begin{array}{l}\text { Baseline NEWS2 } \\
\text { Score }\end{array}$ & $8.7 \pm 0.4$ & $\mathrm{~N} / \mathrm{A}$ \\
\hline $\begin{array}{l}\text { Proportion receiving } \\
\text { dexamethasone } \\
\text { therapy (at some } \\
\text { point during } \\
\text { treatment course) }\end{array}$ & $80.4 \%$ & $100 \%$ \\
\hline $\begin{array}{l}\text { Average length of } \\
\text { stay (days) }\end{array}$ & $14.8 \pm 1.4$ & $18.0 \pm 5.6$ \\
\hline $\begin{array}{l}\text { Mean duration of } \\
\text { ibuprofen therapy } \\
\text { (days)* }^{*}\end{array}$ & $10.1 \pm 0.6$ & $\mathrm{~N} / \mathrm{A}$ \\
\hline
\end{tabular}

Table 2 continued

\begin{tabular}{lll}
\hline $\begin{array}{l}\text { Baseline } \\
\text { characteristic }\end{array}$ & $\begin{array}{l}\text { Nebulized } \\
\text { ibuprofen } \\
(\boldsymbol{n}=\mathbf{5 6})\end{array}$ & $\begin{array}{l}\text { Contemporaneous } \\
\text { control }(\boldsymbol{n}=\mathbf{2 1})\end{array}$ \\
\hline $\begin{array}{l}\text { Mean time in } \\
\text { hospital to death, } \\
\text { deceased patients } \\
(n)\end{array}$ & $13.5 \pm 3.3$ & $15.5 \pm 2.7$ \\
Mortality (\%) & $56 / 11$ & $17 / 21$ \\
& $19.6 \%$ & $80.9 \%^{*}$ \\
\hline
\end{tabular}

${ }^{*} p$ values are statistically significant between the nebulized ibuprofen-treated group and the contemporaneous control group

clinical course reversed dramatically coinciding with initiation of NaIHS therapy. In Fig. 2B and $\mathrm{C}$, the mean daily RR and $\mathrm{SpO}_{2}$ are presented. RR increased during the pre-ibuprofen therapy period, and $\mathrm{SpO}_{2}$ decreased (despite increasing use of supplemental oxygen). Following initiation of NaIHS (arrow) there was steady improvement in mean RR and $\mathrm{SpO}_{2}$. Overall, mean RR normalized ( $\leq 20$ breaths $/ \mathrm{min})$ and mean $\mathrm{SpO}_{2}$ was $>94 \%$, by day 6 , with decreasing numbers of patients on supplemental oxygen during this period.

Average length of hospital stay (ALOS) and duration of therapy (DOT): Among patients not on MV at baseline, the ALOS was $11.5 \pm 0.3$ days for the NaIHS group and $13.3 \pm 0.9$ days for the CC group $(p<0.01)$ (Table 1), with DOT of $9.0 \pm 0.2$ days for the NaIHS group. In this group, 25 patients never required oxygen supplementation; among those receiving oxygen therapy $(n=302)$, the mean duration of oxygen supplementation was 6 days, with a median duration of 5 days. For the 35 patients who progressed to death in the NaIHS group (10.7\%), the ALOS was $13 \pm 1.2$ days, while in the CC group it was $18.8 \pm 2.8$ days ( 34 patients, $p<0.002$ vs. NaIHS group).

Among patients on MV at baseline (Table 2), in the NaIHS group the ALOS was $14.8 \pm 1.4$ days, with DOT of $10.1 \pm 0.6$ days, 
A

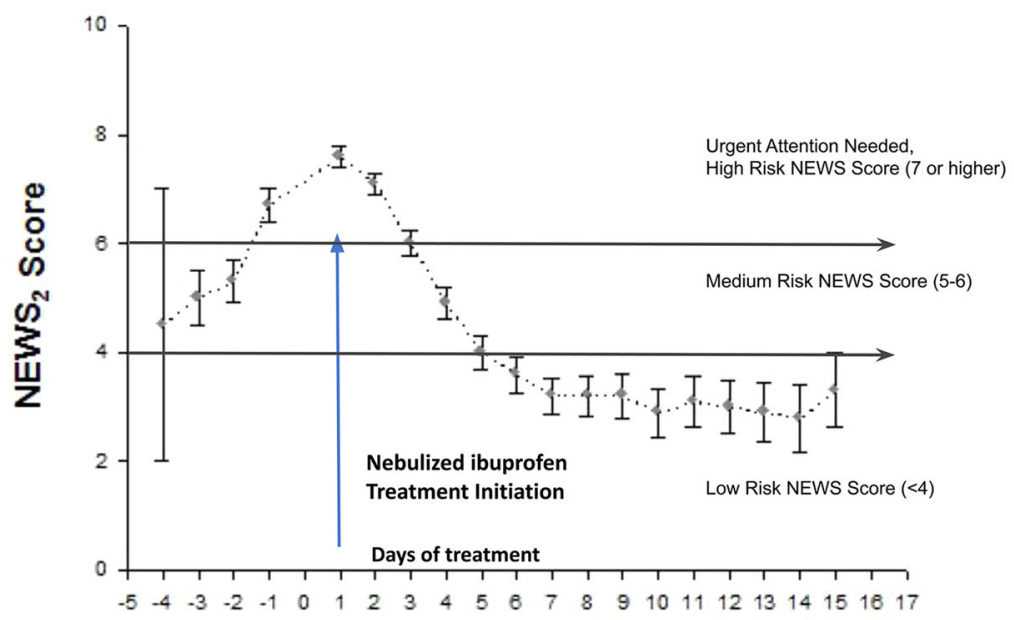

B

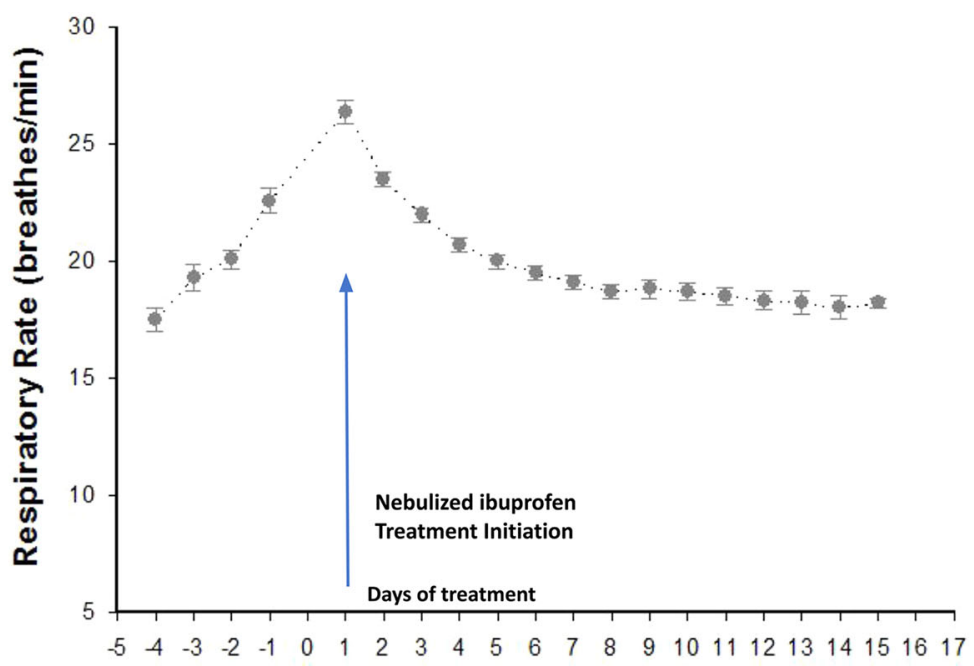

C

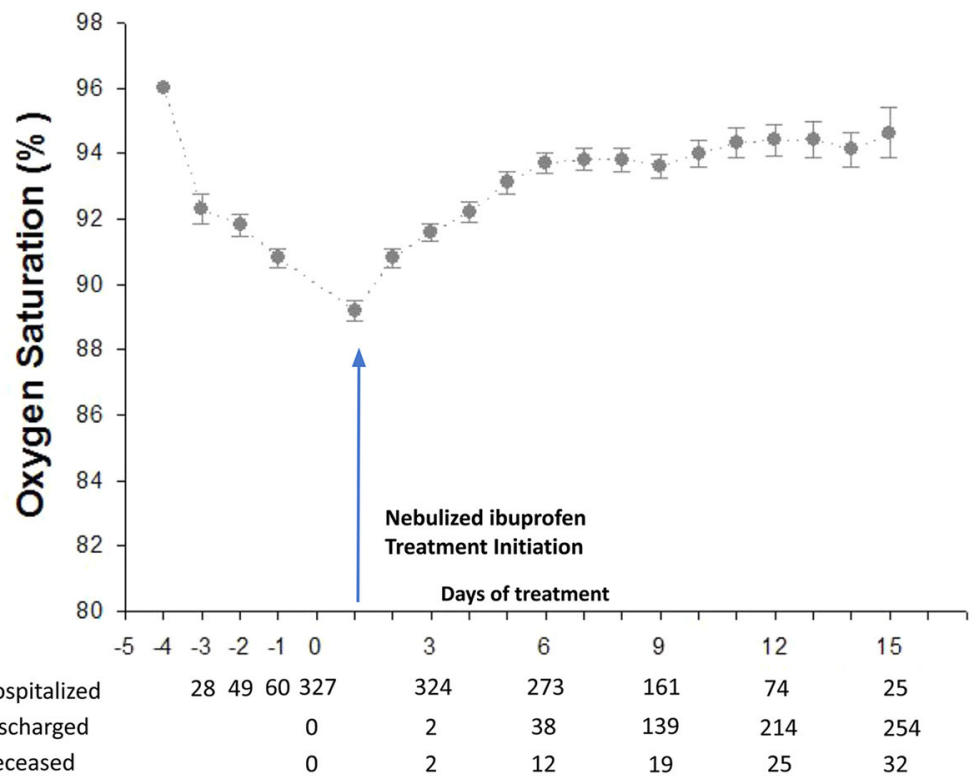

Number of patients Hospitalized Number of patients Discharged Number of patients Deceased

$\begin{array}{cccccl}284960327 & 324 & 273 & 161 & 74 & 25 \\ 0 & 2 & 38 & 139 & 214 & 254 \\ 0 & 2 & 12 & 19 & 25 & 32\end{array}$


4Fig. 2 Evolution of a representative NaIHS-treated group not on MV. Before and after NaIHS treatment started. A NEWS2 Score, $\mathbf{B}$ respiratory rate and $\mathbf{C}$ oxygen saturation among patients not on mechanical ventilation $y$

while in the CC group ALOS was $18.0 \pm 5.6$ days ( $p>0.60$ vs. NaIHS group). For the 11 patients in the NaIHS group who progressed to death in hospital (19.6\%), the ALOS was $13.5 \pm 3.3$ days, while in the CC group $15.5 \pm 2.7$ days for the 17 patients ( $p>0.09$ vs. NaIHS group).

In-hospital mortality rates: Overall in-hospital mortality among patients receiving NaIHS was $12.0 \%(46 / 383)$. At the time of data collection, 28 patients remained in hospital (some for social reasons despite returning to clinical stability). Mortality among NaIHS-treated patients not on MV at baseline was $10.7 \%$, while in those CC patients it was $18.4 \%(p<0.03$ vs. NaIHS group). For those on MV at baseline, mortality was $19.6 \%$ in the NaIHS-treated patients, and $86.7 \%$ in the CC group $(p<0.001$ vs. NaIHS group) (Fig. 1).

For the subset of NaIHS patients not on MV at baseline $(n=327)$, mortality rates were influenced by age and baseline oxygenation status. Among patients $\leq 60$ years, overall mortality was $3.4 \%(6 / 174)$, occurring in 5 patients who presented with baseline $\mathrm{SpO}_{2} \leq 90 \%$, and in 1 who presented with normal oxygenation but died with sepsis (an immunosuppressed renal transplant recipient). Among patients $>$ age 60 , overall mortality was $19.0 \%$ (29/153), the majority of deaths occurring in patients presenting with $\mathrm{SpO}_{2}<90 \%(19 / 29$, $66 \%$ ).

The multiple models' analysis showed that the risk of mortality was significantly lower in those patients under NaIHS treatment (OR 0.45, CI 0.26-0.78), while mechanical ventilation and comorbidities increased the chances of dying by more than twice (OR 2.91, CI 1.51-5.59 and OR 2.24, CI 1.16-4.34), and greater ages with also associated with higher risk (OR 1.06, CI 1.04-1.08), while, as expected, higher $\mathrm{SpO}_{2}$ was associated with lower risk to died (OR 0.90, CI 0.86-0.95).
Concomitant medications: SOC medications administered to the majority of NaIHS-treated patients included: dexamethasone $6 \mathrm{mg} \mathrm{qd}$, (78.4\%), enoxaparin $40 \mathrm{mg}$ sc qd $(81.2 \%)$, and the combination of clarithromycin $500 \mathrm{mg}$ bid and ampicillin-sulbactam 3.0 gr tid (63.2\%).

For the CC patients, $94.6 \%$ received dexamethasone $6 \mathrm{mg}$ qd, enoxaparin $40 \mathrm{mg}$ sc qd and antibiotics, $44 \%$ and $43 \%$, respectively.

A small number of patients received convalescent plasma, ivermectin, or hydroxychloroquine in both groups.

Adverse events: No serious AE were considered directly related to NaIHS. Patients reported mild to moderate cough during the first doses of NaIHS and a salty taste. Bradycardia associated with improved $\mathrm{SpO}_{2}$ was observed in some patients. Three episodes of epistaxis were reported. One patient reported ibuprofen allergy, another claustrophobic reaction due to the hood, and a third patient developed a cough that was considered secondary to nebulization therapy; these three permanently discontinued the medication.

\section{DISCUSSION}

This report describes clinical outcomes in a moderate size cohort of patients with a wide range of COVID-19 severity and treated with NaIHS under a compassionate use protocol. As there was a contemporaneous control, it is not the ideal comparator arm, thus the data can only be considered hypothesis-generating. Despite this limitation, multiple lines of evidence suggest that nebulized NaIHS may be a useful therapeutic tool for the treatment of moderate-to-severe COVID-19, and is worthy of deeper examination in a randomized controlled trial (RCT) context.

The course of multiple critical patient outcome parameters (NEWS2 Scores, RR, and $\mathrm{SpO}_{2}$ ) improved rapidly following the initiation of NaIHS. For the subset of 60 patients for whom these data were available prior to treatment initiation, an acute reversal in trend was observed with a decrease in mean RR coinciding with improving oxygen saturation and NEWS2 scores immediately following initiation of 
therapy. By day 6 following initiation of therapy, mean NEWS2 scores improved to $<4$, pulse oximetry had improved to $\geq 94 \%$ with diminishing supplemental oxygen needs, and RRs had returned to normal. These observations are consistent with the conceptual interpretation that pulmonary delivery of NaIHS diminished bradykinin-storm physiology, likely reduced local prostaglandin and thromboxane synthesis, and acutely improved the ventilation-perfusion mismatch which is a hallmark of this disease, as we hypothesized above.

The overall mortality rate of $10.7 \%$ observed in this study in patients not on MV at baseline compares favorably with the CC group $(19.5 \%$ mortality) and recently published data (Supplemental Table 1). Mortality was twofold higher (19.6\%) among patients on MV at baseline (vs. $10.7 \%$ overall in non-intubated patients), and among non-intubated patients, mortality was strikingly higher among patients $>$ age $60(19.0 \%)$ versus those age 60 or younger (3.4\%) in NaIHS-treated patients.

In the CC group and the published series, mortality rates among patients with severe COVID-19 and on MV at baseline of 13\% [30], and ranging up to $41 \%$ and higher [2] have been reported. While a cross-study comparison of outcomes between trials can only be considered a range-finding exercise for a host of reasons (particularly in the context of continual improvements in care), it is noteworthy that mortality among patients receiving dexamethasone in the RECOVERY trial was over 29\% (noting that most patients in this NaIHS trial received dexamethasone as part of SOC). Recently, results from an Argentinian RCT evaluating treatment with convalescent plasma versus placebo were published [4]. This trial, which excluded patients on MV at screening, reported an overall 28-day mortality rate of approximately $11 \%$, remarkably like the inhospital mortality rate of $10.7 \%$ observed among patients not on MV in the present study.

Importantly, our compassionate use protocol did not exclude patients with profound and confounding major diseases, which would be expected to have increased overall mortality. For instance, among patients enrolled in Buenos Aires, three of the nine deceased patients were admitted with life-threatening illnesses (metastatic pancreatic cancer, bacterial sepsis in a renal transplant recipient, and perforation of the appendix with peritonitis), and subsequently succumbed to these illnesses with concomitant COVID-19 infection. Accordingly, similar mortality rates in the present study point to the possibility of treatment benefit of NaIHS. In this vein of reasoning, despite an effort through exclusion criteria to avoid enrollment of patients in imminent need of intensive care unit admission and MV in the convalescent plasma trial, a total of $85 / 333$ patients $(25.5 \%)$ who were not intubated at baseline ultimately required this intervention. In the present study, clinicians had no restraint preventing enrollment of such patients, yet a smaller proportion (18.9\%) of those not on MV at baseline ultimately required this intervention. Finally, in the convalescent plasma trial [4], the times from intervention to hospital discharge for plasma and placebo treatment were 13 and 12 days, respectively; in our study, the ALOS was $11.5 \pm 0.3$ and $15.5 \pm 1.4$ days for non-ventilated and ventilated groups, respectively. These may be meaningful differences, but of course this can only be assessed in a future RCT. In light of questions raised early in the pandemic regarding the safety of non-steroidal anti-inflammatory drug (NSAID) use in COVID-19 patients, this cross-study comparison should reassure that inhaled ibuprofen does not create excess risk when added to SOC interventions.

The mechanism by which NaIHS induces an apparent rapid improvement in oxygenation and other vital signs in COVID-19 patients is unknown, but multiple potential mechanisms can be evoked. These include the classical antiinflammatory activity mediated by inhibition of prostaglandin and bradykinin synthesis, inhibition of thromboxane's platelet aggregation, and reduction of reactive oxygen species by polymorphonuclear cells, as previously observed [27]. A potential benefit of nebulized hypertonic saline, recognized to be a mucolytic agent and used for this purpose in the treatment of cystic fibrosis and bronchiectasis, should not be overlooked. Finally, both direct antiviral and antibacterial activity, as well as potential 
indirect antiviral activity through inhibition of RhoGTPase activity, may have contributed.

This beneficial effect induced by ibuprofen is not unique in COVID-19 pneumonia, as this has also been reported in other lung diseases, such as cystic fibrosis, and it was found to slow the progression of lung disease in children [31]. Additionally, the effect of other NSAIDs was evaluated in non-small cell lung cancer (NSCLC), the most frequent lung cancer observed. NSCLC overexpresses COX-2, which contributes to the progression of malignancy, thus inhibition of COX-2 favors apoptosis and inhibition of angiogenesis, and decreases invasiveness and metastatic potential [32].

This program of course has limitations. First, this is a description of a non-randomized observational cohort receiving compassionate use therapy compared with a CC group, and causal relationships to outcomes cannot be proven. During this pandemic, no treatment has been available, and lethality is high. Many compassionate treatments, such as antivirals, convalescent serum, or plasma from recovered patients, chloroquine, azithromycin, and ivermectin, have been reported as possibly effective based on the known properties of these drugs, but in proper clinical trials, all were later dismissed as not useful and even dangerous. To evaluate the effectiveness of NaIHS in COVID19 pneumonia, we are conducting a Phase II trial in Argentina (ANMAT \#Expte 1-0047-0002000699-20-9; Pegasus) hoping to end by the end of the year. Second, only hospitalized adults were evaluated, and the findings may not be generalizable to other populations, including non-hospitalized patients. Third, given the nature of the study, many critical parameters were not prospectively evaluated (pharmacovigilance, $\mathrm{FiO}_{2}$ ). Finally, only a single dosing regimen of ibuprofen was studied. Despite these limitations, encouraging efficacy trends emerged.

\section{CONCLUSION}

The compassionate use of sodium ibuprofenate administered by nebulization in hypertonic saline appeared to be safe and well-tolerated in this cohort with varying severity of illness. Average length of stay and mortality rates compared favorably with published outcomes from RCTs. Reversal of deleterious physiologic trends, overall coincided with the initiation of treatment. NaIHS appears to be a promising therapy for treatment of COVID-19 pneumonitis, warranting further evaluation in RCTs.

\section{ACKNOWLEDGEMENTS}

We thank Drs. Ernesto Jakob and Flavio Lipari (infectologists), Drs. Julio Bartoli, Ignacio Ledesma (intensivists), for assistance during the protocol development and the participants of the study.

Funding This work was supported by funds from the Química Luar SRL, who provided NaIHS under compassionate use. This funding body had no role in: the design of the study; the collection, analysis, or interpretation of data; and the writing of the manuscript. The journal's Rapid Service Fee was funded by the Química Luar SRL.

Authorship All named authors meet the International Committee of Medical Journal Editors (ICMJE) criteria for authorship for this article, take responsibility for the integrity of the work as a whole, and have given their approval for this version to be published.

Authorship Contributions Conceptualization: Pablo Alexis Doreski, Germán Ambasch, Luis Alberto Argañarás, Nicolás Martínez Ríos, Dante Miguel Beltramo and Néstor Horacio García. Data curation: Sonia Edith Muñoz, Mariana Natalia Carrillo, Daniela Josefina Porta, Hernán Alejandro Pérez, Néstor Horacio García. Formal analysis: Pablo Alexis Doreski, Sonia Edith Muñoz, Mariana Natalia Carrillo, Daniela Josefina Porta, Hernán Alejandro Pérez, Dante Miguel Beltramo, Néstor Horacio García. Funding acquisition: Luis Alberto Argañarás, Nicolás Martínez Ríos and Galia Ines Kalayan. Investigation: Oscar Salva, Celia Sara Giler, Dario Conrado Quinodoz, Lucia Guadalupe Guzmán, Germán Ambasch, Esteban Coscia, Jorge Luis 
Tambini Díaz, Germán David Bueno, Jorge Oscar Fandi, Miriam Angélica Maldonado, Leandro Eugenio Peña Chiappero, Fernando Fournier, Hernán Alejandro Pérez, Mauro Andrés Quiroga, Javier Agustín Sala Mercado, Marcelo Alejandro Beltrán, Carlos Martínez Picco, Methodology: Luis Alberto Argañarás, Nicolás Martínez Ríos, Dante Miguel Beltramo, Néstor Horacio García. Project administration: Luis Alberto Argañarás, Nicolás Martínez Ríos, Galia Inés Kalayan. Resources: Luis Alberto Argañarás and Nicolás Martínez Ríos. Supervision: Luis Alberto Argañarás, Nicolás Martínez Ríos, Néstor Horacio García. Software: Hernán Alejandro Pérez. Validation: Oscar Salva, Pablo Alexis Doreski, Néstor Horacio García. Visualization: Néstor Horacio García. Writing-original draft: Néstor Horacio García. Writingreview and editing: Pablo Alexis Doreski, Dario Conrado Quinodoz, Luis Alberto Argañarás, Nicolás Martínez Ríos, Dante Miguel Beltramo, Néstor Horacio García.

Disclosures All named authors confirm that they have no conflicts of interest to declare.

Compliance with Ethics Guidelines Ethical approval was obtained from the Institutional Independent Ethics Committees and district regulatory agencies of Córdoba and Mendoza Provinces for the compassionate use of Luarprofeno $^{\circledR}$ (sodium ibuprofenate in hypertonic saline, or NaIHS, for nebulization). The program was carried out in accordance with the principles of the Declaration of Helsinki for Buenos Aires. All participating individuals were $\geq$ age 18 and provided written informed consent, obtained by the treating physician.

Data Availability The datasets used and analyzed during the current study are available from the corresponding author in response to reasonable requests.

Open Access. This article is licensed under a Creative Commons Attribution-NonCommercial 4.0 International License, which permits any non-commercial use, sharing, adaptation, distribution and reproduction in any medium or format, as long as you give appropriate credit to the original author(s) and the source, provide a link to the Creative Commons licence, and indicate if changes were made. The images or other third party material in this article are included in the article's Creative Commons licence, unless indicated otherwise in a credit line to the material. If material is not included in the article's Creative Commons licence and your intended use is not permitted by statutory regulation or exceeds the permitted use, you will need to obtain permission directly from the copyright holder. To view a copy of this licence, visit http:// creativecommons.org/licenses/by-nc/4.0/.

\section{REFERENCES}

1. WHO Coronavirus (COVID-19) Dashboard [Internet]. https://covid19.who.int. Accessed 2021 June 29.

2. The RECOVERY Collaborative Group. Dexamethasone in Hospitalized Patients with Covid-19. N Engl J Med. 2021;384(8):693-704.

3. Repurposed Antiviral Drugs for Covid-19-Interim WHO Solidarity Trial Results. N Engl J Med. 2021;384(6):497-511.

4. Simonovich VA, Burgos Pratx LD, Scibona P, Beruto $\mathrm{MV}$, Vallone $\mathrm{MG}$, Vázquez $\mathrm{C}$, et al. A randomized trial of convalescent plasma in COVID-19 severe pneumonia. N Engl J Med. 2021;384(7):619-29.

5. Cao B, Wang Y, Wen D, Liu W, Wang J, Fan G, et al. A Trial of Lopinavir-Ritonavir in adults hospitalized with severe COVID-19. N Engl J Med. 2020;382(19): 1787-99.

6. Cavalcanti AB, Zampieri FG, Rosa RG, Azevedo LCP, Veiga VC, Avezum A, et al. Hydroxychloroquine with or without Azithromycin in Mild-to-Moderate COVID-19. N Engl J Med. 2020;383(21):2041-52.

7. Stone JH, Frigault MJ, Serling-Boyd NJ, Fernandes AD, Harvey L, Foulkes AS, et al. Efficacy of tocilizumab in patients hospitalized with COVID-19. N Engl J Med. 2020;383(24):2333-44.

8. Shi H, Han X, Jiang N, Cao Y, Alwalid O, Gu J, et al. Radiological findings from 81 patients with COVID- 
19 pneumonia in Wuhan, China: a descriptive study. Lancet Infect Dis. 2020;20(4):425-34.

9. Ackermann M, Verleden SE, Kuehnel M, Haverich A, Welte $\mathrm{T}$, Laenger $\mathrm{F}$, et al. Pulmonary vascular endothelialitis, thrombosis, and angiogenesis in COVID-19. N Engl J Med. 2020;383(2):120-8.

10. Garvin MR, Alvarez C, Miller JI, Prates ET, Walker $\mathrm{AM}$, Amos BK, et al. A mechanistic model and therapeutic interventions for COVID-19 involving a RAS-mediated bradykinin storm. Elife. 2020;9: e59177.

11. Brito-Azevedo A, Pinto EC, Cata Preta CGA, Bouskela E. SARS-CoV-2 infection causes pulmonary shunt by vasodilatation. J Med Virol. 2021;93(1): 573-5.

12. Baraniuk JN, Lundgren JD, Mizoguchi H, Peden D, Gawin A, Merida M, et al. Bradykinin and respiratory mucous membranes: analysis of bradykinin binding site distribution and secretory responses in vitro and in vivo. Am Rev Respir Dis. 1990;141(3):706-14.

13. Gholamreza-Fahimi E, Bisha M, Hahn J, Straßen U, Krybus M, Khosravani F, et al. Cyclooxygenase activity in bradykinin-induced dermal extravasation. A study in mice and humans. Biomed Pharmacother. 2020;123:109797.

14. McFadyen JD, Stevens H, Peter K. The emerging threat of (Micro)thrombosis in COVID-19 and its therapeutic implications. Circ Res. 2020;127(4): 571-87.

15. Magro C, Mulvey JJ, Berlin D, Nuovo G, Salvatore S, Harp J, et al. Complement associated microvascular injury and thrombosis in the pathogenesis of severe COVID-19 infection: a report of five cases. Transl Res. 2020;220:1-13.

16. Mcintyre BA, Philp RB, Inwood MJ. Effect of ibuprofen on platelet function in normal subjects and hemophiliac patients. Clin Pharmacol Ther. 1978;24(5):616-21.

17. Walsh S. Low-dose aspirin: treatment for the imbalance of increased thromboxane and decreased prostacyclin in preeclampsia. Am J Perinatol. 1989;6(02):124-32.

18. Hammock BD, Wang W, Gilligan MM, Panigrahy D. Eicosanoids. Am J Pathol. 2020;190(9):1782-8.

19. Serhan CN. Systems approach to inflammation resolution: identification of novel anti- inflammatory and pro-resolving mediators. J Thromb Haemost. 2009; 7:44-8.

20. Das UN. Can bioactive lipids inactivate coronavirus (COVID-19)? Arch Med Res. 2020;51(3):282-6.

21. Muñoz A, Alasino R, Garro A, Heredia V, García N, Cremonezzi D, et al. High concentrations of sodium chloride improve microbicidal activity of ibuprofen against common cystic fibrosis pathogens. Pharmaceuticals. 2018;11(2):47.

22. Swaine T, Dittmar M. CDC42 use in viral cell entry processes by RNA viruses. Viruses. 2015;7(12): 6526-36.

23. Freeman MC, Peek CT, Becker MM, Smith EC, Denison MR. Coronaviruses induce entry-independent, continuous macropinocytosis. mBio [Internet]. 2014. https://doi.org/10.1128/mBio.01340-14.

24. Zamudio-Meza H, Castillo-Alvarez A, GonzálezBonilla C, Meza I. Cross-talk between Rac1 and Cdc42 GTPases regulates formation of filopodia required for dengue virus type- 2 entry into HMEC-1 cells. J Gen Virol. 2009;90(12):2902-11.

25. Zhou Y. Nonsteroidal anti-inflammatory drugs can lower amyloidogenic A 42 by inhibiting rho. Science. 2003;302(5648):1215-7.

26. Dill J, Patel AR, Yang X-L, Bachoo R, Powell CM, Li S. A molecular mechanism for ibuprofen-mediated RhoA inhibition in neurons. J Neurosci. 2010;30(3): 963-72.

27. García NH, Porta DJ, Alasino RV, Muñoz SE, Beltramo DM. Ibuprofen, a traditional drug that may impact the course of COVID-19 new effective formulation in nebulizable solution. Med Hypotheses. 2020;144:110079.

28. Smith GB, Redfern OC, Pimentel MA, Gerry S, Collins GS, Malycha J, et al. The National Early Warning Score 2 (NEWS2). Clin Med. 2019;19(3): 260-260.

29. McCullagh P, Nelder JA. Generalized linear models (monographs on statistics and applied probability). 2nd ed. Boca Raton: Chapman \& Hall/CRC; 1998.

30. Beigel JH, Tomashek KM, Dodd LE, Mehta AK, Zingman BS, Kalil AC, et al. Remdesivir for the treatment of COVID-19-final report. N Engl J Med. 2020;383(19):1813-26.

31. Konstan MW, Byard PJ, Hoppel CL, Davis PB. Effect of high-dose ibuprofen in patients with cystic fibrosis. N Engl J Med. 1995;332(13):848-54. 
32. Tsubouchi Y, Mukai S, Kawahito Y, Yamada R, Kohno $\mathrm{M}$, Inoue $\mathrm{K}$, et al. Meloxicam inhibits the growth of non-small cell lung cancer. Anticancer Res. 2000;20(5A):2867-72.

\section{Publisher's Note}

Springer Nature remains neutral with regard to jurisdictional claims in published maps and institutional affiliations. 